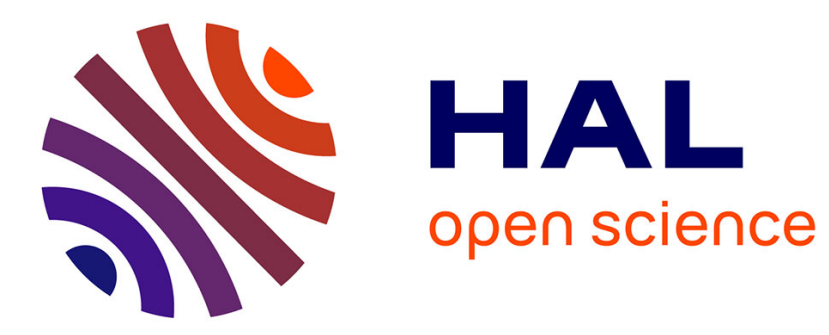

\title{
A General Concept Concerning Energetic Material Sensitivity and Initiation [1]
}

\author{
S. Shackelford
}

\section{To cite this version:}

S. Shackelford. A General Concept Concerning Energetic Material Sensitivity and Initiation [1]. Journal de Physique IV Proceedings, 1995, 05 (C4), pp.C4-485-C4-499. 10.1051/jp4:1995439 . jpa00253744

\section{HAL Id: jpa-00253744 https://hal.science/jpa-00253744}

Submitted on 1 Jan 1995

HAL is a multi-disciplinary open access archive for the deposit and dissemination of scientific research documents, whether they are published or not. The documents may come from teaching and research institutions in France or abroad, or from public or private research centers.
L'archive ouverte pluridisciplinaire HAL, est destinée au dépôt et à la diffusion de documents scientifiques de niveau recherche, publiés ou non, émanant des établissements d'enseignement et de recherche français ou étrangers, des laboratoires publics ou privés. 


\title{
A General Concept Concerning Energetic Material Sensitivity and Initiation [1]
}

\author{
S.A. Shackelford [2]
}

Alliance Pharmaceutical Corp., 3040 Science Park Road, San Diego, CA 92121, U.S.A.

\begin{abstract}
Stimulation and propagation of an energetic material to a catastrophic explosive event could be described as a interactive transfer of mechanistic mechanical, physical, and chemical processes progressing through an "initiation train" sequence, which begins at the bulk material level, next proceeds into the microstructural regime, then to the molecular level, and finally reaches into the atomic region. These mechanistic processes comprising this sequential initiation train serve several functions. First, some create the physically-structured environment and conditions in the initiation train which are needed to house and propagate other mechanisms associated with energy functions and chemical reaction pathways. Secondly, other detailed mechanisms define the orderly transfer and conversion of energy generated during the initiation train sequence, and thirdly, still other detailed mechanisms provide the kinetically-regulated chemical reactions which control energy release rates and provide the intermediate and final chemical product species which drive the detonation wave front. The rate at which these various mechanisms occur in the initiation train defines the sensitivity of an energetic material. This initiation train concept, its potential for controlling sensitivity, and the relevance of certain mechanistic aspects and data as component parts in this initiation train are outlined.
\end{abstract}

\section{INTRODUCTION}

Initiation of an energetic material and its accelerator propagation to a catastrophic event like combustion , thermal explosion, or full-scale detonation event occurs when localized self-heating accelerates in the bulk material more rapidly than it can be dissipated within a specific but relatively short time period. Over the past twenty years, a number of scientists have conducted numerous fundamental investigations into various mechanistic processes which appear to contribute to energetic material initiation. Basically, these mechanistic investigations could be divided into three categories: mechanical, physical or physicochemical, and chemical. Various kinds of mechanisms have been theoretically proposed, computationally modeled, or experimentally studied which involve either, the physical environment in which the initiation event occurs, the energy functions associated with energy transfer, conversion and release rates, or chemical pathways associated with molecular structure, reaction rates, and product formation.

Within the past ten years, the energetic materials community also has come to recognize that, during initiation, various mechanisms occur at different levels or scales of energetic material substance composition. These substance composition levels can be described as the macroscopic level involving the bulk material, the microscopic level describing crystal structure considerations, the molecular level describing both the chemical structure and the chemical reactions, and finally, the atomic level involving individual atoms derived from the original energetic compound. These mechanisms, occurring at various compositional levels of an energetic material, each are integral parts of a much larger and complex event. While detailed information still is needed about the mechanistic intricacies of each mechanistic process, there also is a challenge which requires the blending of these into one complete or overall mechanistic 
description of the entire initiation event. Simply stated, these individual mechanistic pieces must be properly fit into one large coherent picture which accurately describes the initiation event and which properly describes the interactions occurring among the various mechanistic processes at each of the compositional levels.

This paper introduces a general concept concerning energetic material initiation and sensitivity. It attempts to provide a coherent framework, albeit in a preliminary form, within which this large coherent picture might eventually be assembled. Certain key fundamental research studies involving a number of distinguished scientists are described and cited which illustrate and support various facets of this conceptual initiation train concept. Because of space and time limitations, not all fundamental investigations which might be relevant to this conceptual model, nor the scientific investigators associated with these studies, all can be mentioned, and their omission is not intended to slight the importance of their work nor the contributions of the scientists who conducted them. Additionally, it is anticipated the presentations at this workshop will uncover other new aspects of the initiation event which would nicely dovetail into or require a modification of this preliminary initiation train concept.

\section{DISCUSSION}

Figure 1 represents a general concept concerning the overall energetic material initiation event. It illustrates an "initiation train" comprised of sequential mechanistic mechanical, physical or

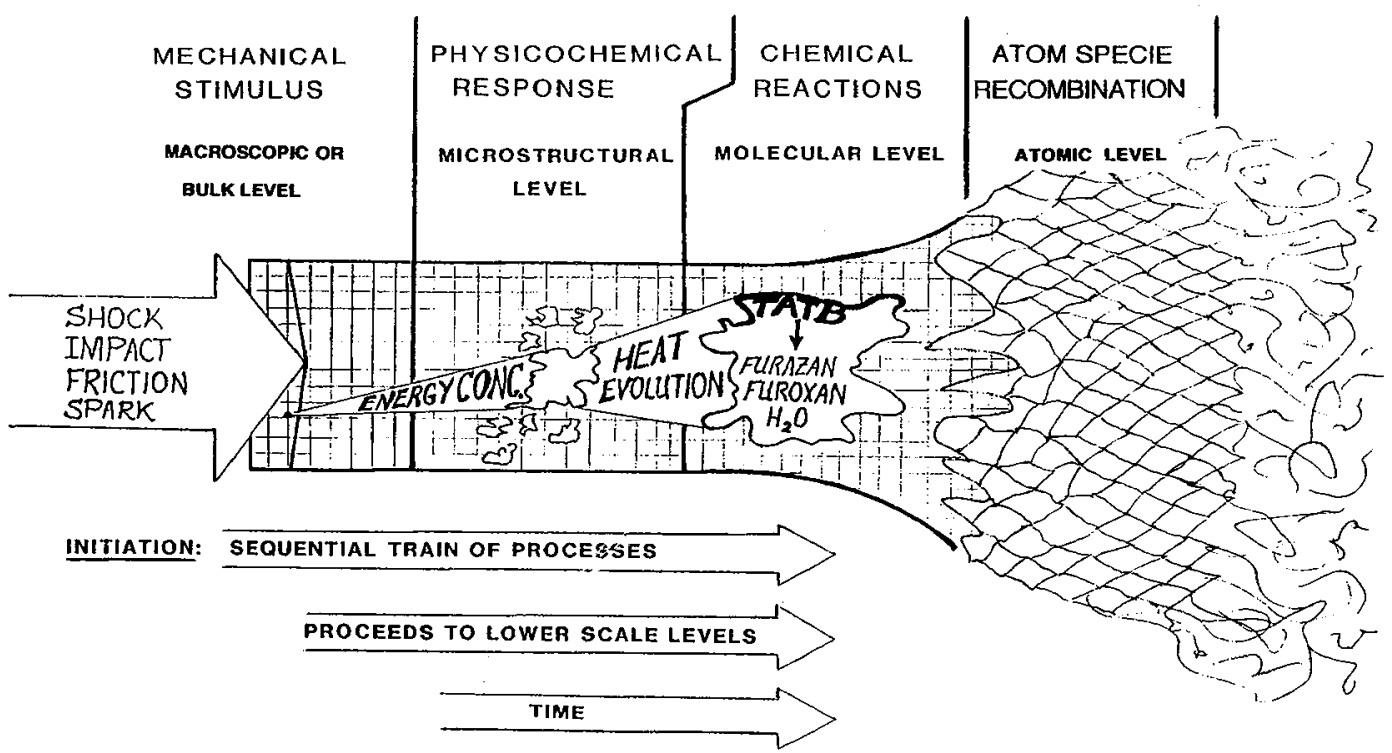

Figure 1. General Pictorial Concept of the Initiation Train Sequence.

physicochemical, and chemical reaction processes which begin with the bulk energetic material at the macroscopic level. It then proceeds into the microscopic level involving the crystal lattice characteristics plus energy behavior of the energetic material. Next, the initiation event moves into the molecular level where chemical reactions generated by a rapid thermochemical decomposition occur; and finally, it proceeds into the atomic level where atomized species form and recombine into the final small gaseous molecules detected as detonation products. It meets the criteria of an event which (a) is sequential in nature, (b) proceeds progressively into more minute material composition levels, and (c) occurs over a very rapid but finite time period. It also contains three other elements which seem to be common with most mechanistic processes studied as part of the initiation event; these would be, (1) the formation of a physical environment in which other mechanisms may proceed, (2) the evolution, conversion, or transfer of heat energy, and (3) the presence of chemical reactions which rapidly decompose the original energetic compound into other chemical compounds with a concomitant energy release. 
All types of mechanisms investigated with the initiation event seem to accomplish either one of three functions. Firstly, they ensure formation of the physical environment and resultant conditions which house processes required for the conversion of mechanical energy into heat energy, for the transfer and concentration of heat energy, or for the degradation of the original compound via rapid thermochemical decomposition reactions. Secondly, they provide for the actual conversion of mechanical energy into heat and the transfer and conversion of heat energy. Thirdly, they generate a pathway followed by the heat-generated thermochemical decomposition reactions which produce the intermediate and final product species driving the detonation wave front.

Beginning at the left side of Figure 1, the initiation train scenario might proceed as follows. An external stimulus (impact, shock, friction, spark, heat) on the bulk energetic material at the macroscopiç level, introduces a physical response (fracture, shear, viscous flow, plastic deformation, gas bubble pressure and others) [2-21] at the microscopic level which forms new microstructural defects or locates already existing inhomogeneities in crystal lattice of the energetic material. These microstructural defects then each serve as a highly localized nucleation point where mechanical energy is concentrated and converted into heat energy at the microscopic level via some type of physical or physicochemical mechanism. This conversion and concentration of heat in the micron-sized or submicron defect produces a hot spot in which an extremely high pressure and high temperature build up rapidly occurs. Within the hot spot on its inner surface, heat activated thermochemical decomposition reactions begin to occur at the molecular level where some of the heat energy is converted into the kinetic energy needed to activate and drive, perhaps by radical species catalysis, the thermochemical decomposition process and its associated chemical mechanism(s). The kinetically-controlled chemical reactions, generated during the rapid thermochemical decomposition process, produce more sensitive condensed phase intermediate compounds which themselves break down further into gaseous products with more heat evolution. Eventually, this rapid decomposition causes these intermediate condensed phase and gaseous products to reach the atomic structural level by producing atomized species. The recombination of these atomic species into final gaseous detonation products occurs in a cellular-structured environment found to exist behind the detonation shock wave. The fracture, cracking, and shear interfaces occurring at the bulk macroscopic level, the hot spots created at the microscopic level, and the cellular structure inherent with the detonation wave, formed by either mechanical or physical mechanistic responses, represent physically-structured features which define an environment and the parametric conditions where other mechanisms can operate to either generate, transfer, and convert heat energy, or where kineticallycontrolled reaction mechanisms provide the necessary chemical species and energy release rates needed to propagate and sustain a detonation event.

A number of theoretical and experimental mechanistic investigations lend support to this concept. Mechanisms (1) by which mechanical stimuli are converted into physical responses at the bulk level, (2) mechanisms by which these physical responses generate and propagate the formation of localized microstructural defects or inhomogeneities; and (3) mechanisms by which these physical responses convert and concentrate their energy into heat to form hot spots have been covered in the literature and at various scientific conferences, workshops, and symposia [2-21]. Some of these mechanistic responses are recognized by the following terms: fracture, shear, viscous flow, plastic deformation, gas bubble pressure, and others. One mechanistic process for which extensive experimental evidence has been gathered, is termed the "Dislocation Pile-Up Avalanche Mechanism" [21]. It describes the conversion of a mechanical stimulus (impact) at the macroscopic bulk level into a physicochemical response known as plastic deformation, which introduces shear bands into the crystalline material. This causes a rapid avalanche type of build-up for microscopic level defects and concentrates heat at these localized points to form hot spots with a concomitant generation of radical species [8,21]. Possibly, these radical species catalyze the initiation of molecular level thermochemical decomposition reactions inside the hot spots.

The potential catalytic role of radicals is illustrated by both theoretical and experimental investigations of crystal structure orientation and sensitivity. Radicals can form along with defects during microscopic level crystal lattice shearing. Theoretical calculations conducted on an initiation model of nitromethane initiation predicted certain crystal orientations of the solid nitromethane crystal lattice would initiate to detonation more easily than others [22]. This effect was noted in an experimental study of solid nitromethane where explosive behavior in a diamond-anvil cell was found to be dependent on crystal orientation [23]. A model invoking steric hindrance in the movement of one molecule of nitromethane past other molecules during shear deformation of the crystal lattice explained this behavior and illustrated that covalent bond rupture occurs more readily in sterically hindered orientations where one molecule 
collides with another [23]. PETN also displays a crystal orientation dependence with its shock initiation sensitivity, and this behavior also is attributed to steric hindrance of molecular motion in the shear flow [24]. The dependence of detonation velocity with various crystal orientations in RDX [25], conceivably, also may result in part from radicals being generated as molecules collide in the more sterically hindered orientations and homolytic bond ruptures occur. Thus, microscopic level mechanistic processes produce hot spots and radicals which, in turn, must contribute to starting the molecular level thermochemical decomposition reactions in the hot spots.

The actual existence and role of hot spots was experimentally verified by scanning electron microscopy (SEM) and X-ray Photoelectron Spectroscopy (XPS) analyses of energetic materials which were impacted or shocked just below their initiation threshold [26-29]. Micron-sized (impact) and submicronsized (shock) quenched hot spots with charred inner surfaces were located by the SEM technique, and XPS analysis of these charred surfaces inside the hot spots revealed new condensed phase intermediate products formed from the original energetic compound. The new condensed phase intermediate compounds resulted from the chemical reactions associated with the rapid thermochemical decomposition process which produced the charred inner hot spot surface. At the molecular level, this thermochemical decomposition process in sub-initiated TATB produced much more sensitive furoxan compounds as well as furazan compounds in this charred hot spot surface (Figure 2). At this point, the chemical kinetics of the rapid thermochemical decomposition process and their role in molecular level chemical reactions must be considered.

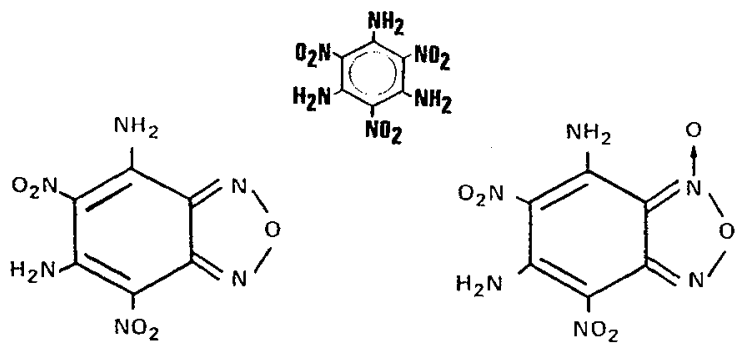

\section{MONOFURAZAN}

\section{MONOFUROXAN}

Figure 2. Hot Spot Char Products in TATB Sub-Initiation by Mechanical Impact [29].

The role of chemical kinetics in regulating chemical reaction rates and resultant energy release rates during the thermochemical decomposition process, first was demonstrated with TNT using the kinetic deuterium isotope effect (KDIE) approach [30]. In this mechanistic investigation, the hydrogen atoms in TNT's pendant methyl group were replaced with deuterium atoms (TNT-d3) and the ambient pressure thermochemical decomposition rate was measured for both the normal TNT and deuterated TNT-d3 using isothermal differential scanning calorimetry (IDSC) [30]. Introduction of deuterium atoms to form a stronger $\mathrm{C}-\mathrm{D}$ bond in the TNT-d3 pendant methyl group (Figure 3), slowed its thermochemical decomposition rate significantly enough to reveal that methyl group $\mathrm{C}-\mathrm{H}$ bond dissociation $\left(1^{\circ} \mathrm{KDIE}\right)$ controlled the overall rate of the TNT thermochemical decomposition process. Subsequent KDIE studies with the normal HMX and deuterated HMX-d8 $[31,34]$ cyclic nitramine compounds indicated the same condensed-phase dependent rate-controlling step exists ( $\mathrm{C}-\mathrm{H}$ bond dissociation), whether $\mathrm{HMX}$ is involved in an ambient pressure solid-phase thermochemical decomposition process, a rapid solid-phase pyrolysis process (ambient pressure), or a high pressure/high temperature combustion event $[31,35]$. KDIE investigations with $\mathrm{RDX}$ and $\mathrm{RDX}-\mathrm{d} 6$ showed the same rate-controlling $\mathrm{C}-\mathrm{H}$ bond rupture in both its solid- and liquid-phase thermochemical decomposition processes [32,36-38] and in its high pressure combustion event [39]. KDIE studies with TATB and TATB-d6 also revealed the same rate-controlling $\mathrm{N}-\mathrm{H}$ bond rupture in the pendant amino group for the ambient pressure thermochemical decomposition process $[40,41]$ and the initiation sensitivity of its thermal explosion event [40]. Additionally, a shock initiated detonation study with HMX, RDX, and TNT, plus their deuterated analogues (HMX-d8, RDX$\mathrm{d}_{6}$, and TNT-d 3 , respectively), revealed a slight yet statistically significant difference in initiation sensitivity; the deuterated analogues were more difficult to initiate indicating a probable contribution 


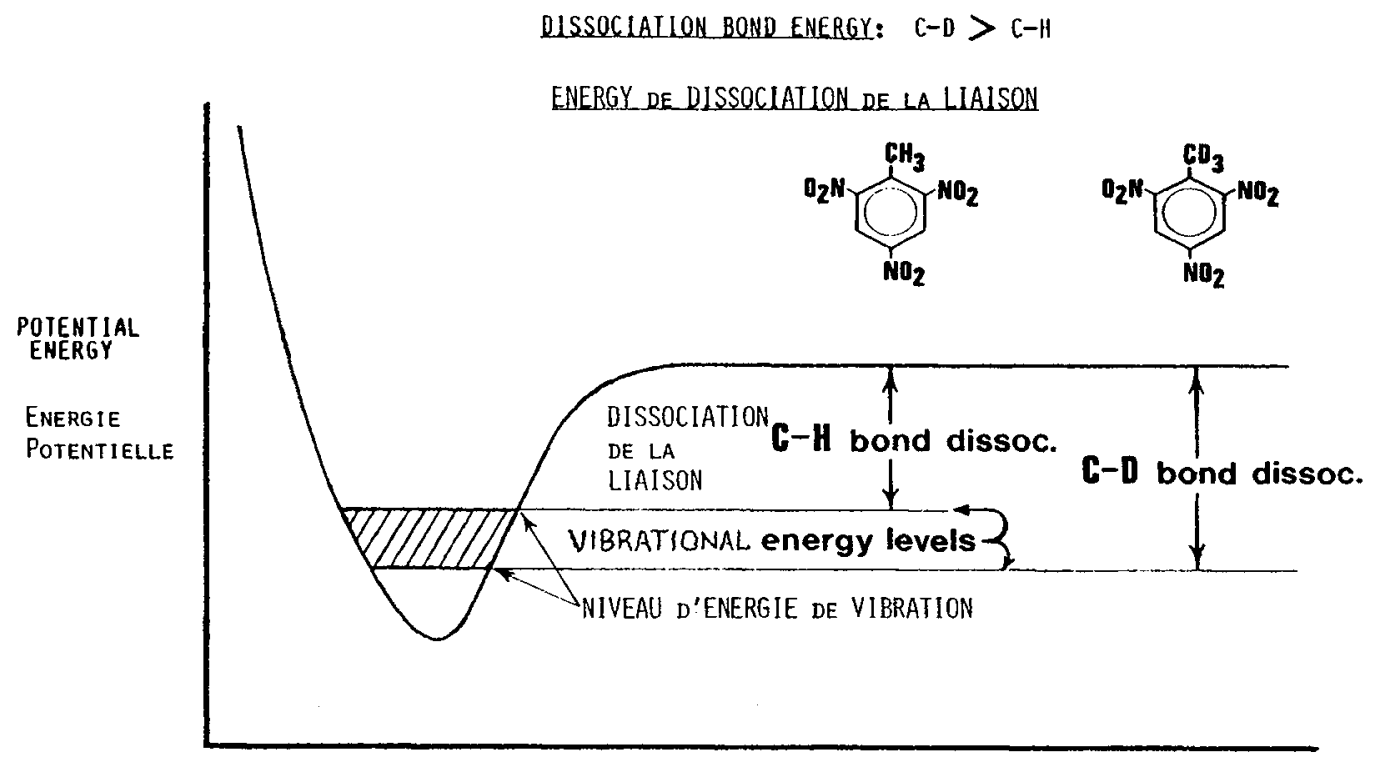

DIATOMIC INTERNUCLEAR DISIANCE

DISTANCE INTERNUCLEAIRE ENTRE DEUX ATOMES

Figure 3. Zero Point Vibrational Energy Difference Between Covalent C-H and C-D Bond Dissociation.

from a rate-controlling $\mathrm{C}-\mathrm{H}$ bond rupture in the initiation event $[32,42]$. Figure 4 illustrates the KDIEdetermined rate-controlling step in the thermochemical decomposition of the four energetic compounds mentioned. Note the rate-controlling step of HMX apparently varies depending upon its physical state when decomposition is proceeding.

THERMOCHEMICAL DECOMPOSITION RATE-CONTROLLING-STEP (RCS)
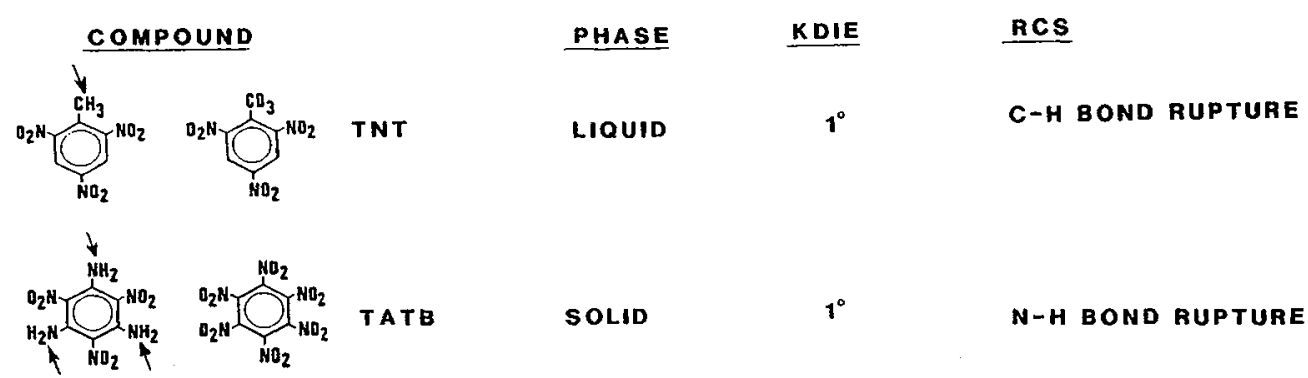

$\begin{array}{lrl}\text { SOLID } & 1^{\circ} & \text { N-H BOND RUPTURE } \\ \text { SOLID } & 1^{\circ} & \text { C-H BOND RUPTURE } \\ \text { LIQUID } & 1^{\circ} & \text { C-H BOND RUPTURE } \\ \text { SOLID } & 1^{\circ} & \text { C-H BOND RUPTURE } \\ \text { MIXED MELT } & \text { InV. } & \text { INTERMOL CRYST. FORCES } \\ \text { LIQUID } & 2^{\circ} & \text { C-N BOND RUPTURE }\end{array}$

Figure 4. Rate-Controlling Step in Ambient Pressure Thermochemical Decompositon Process. 
Table I summarizes the various KDIE-determined rate-controlling steps detected for a number of energetic materials in different mechanistic processes (thermal decomposition and rapid pyrolysis) and high energy releasing events (combustion, thermal explosion, detonation) [43]. A consideration of all these KDIE results suggests that chemical kinetics play a significant role in controlling the rate of energy release and product formation during the initiation event. It further suggests that chemical kinetics must constitute one significant factor in the initiation train which directly affects the sensitivity of an energetic material toward initiation, and does so by exerting a certain degree of kinetic control on the overall

Table I

\begin{tabular}{|c|c|c|c|c|c|}
\hline Compound & Event & Physical Stat & $\underline{\text { KDIE }}$ & $\underline{\mathbf{R C S}}$ & $\underline{\text { Reference }}$ \\
\hline TNT & td & Liquid & $1^{\circ}$ & methyl C-H & 30 \\
\hline TNT & det & $?$ & $1^{\circ}(?)$ & methyl C-H(?) & 42 \\
\hline TATB & $t d$ & Solid & $1^{\circ}$ & amino $\mathrm{N}-\mathrm{H}$ & 40 \\
\hline TATB & te & $?$ & $1^{\circ} *$ & amino $\mathrm{N}-\mathrm{H}$ & 40 \\
\hline HMX & td & Solid & $1^{\circ}$ & C-H & $31-34$ \\
\hline HMX & td & Mixed Melt & Inverse & $\begin{array}{l}\text { Internal Cryst } \\
\text { Lattice Forces }\end{array}$ & 31 \\
\hline HMX & td & Liquid & $2^{\circ}$ & Ring $\mathrm{C}-\mathrm{N}$ & 31 \\
\hline HMX & te & Mixed Melt & Inverse* & $\begin{array}{l}\text { Internal Cryst } \\
\text { Lattice Forces }\end{array}$ & 31 \\
\hline HMX & comb & Solid & $1^{\circ}$ & $\mathrm{C}-\mathrm{H}$ & 35 \\
\hline HMX & det & $?$ & $1^{\circ}$ or $2^{\circ}$ & $\mathrm{C}-\mathrm{H}$ or $\mathrm{C}-\mathrm{N}$ & 32 \\
\hline RDX & td & Solid & $1^{\circ}$ & C-H & 32,37 \\
\hline RDX & td & Liquid & $1^{\circ}$ & C-H & $32,36,37$ \\
\hline RDX & comb & $?$ & $1^{\circ}$ & $\mathrm{C}-\mathrm{H}$ & 39 \\
\hline RDX & $\operatorname{det}$ & $?$ & $1^{\circ}$ or $2^{\circ}$ & $\mathrm{C}-\mathrm{H}$ or $\mathrm{C}-\mathrm{N}$ & 32 \\
\hline $\begin{array}{l}\text { comb }=\text { com } \\
\text { det }=\text { deton }\end{array}$ & $\begin{array}{l}\text { ustic } \\
\text { ion }\end{array}$ & ling Step & $\begin{array}{r}=\text { thermoc } \\
\text { te }=\text { ther } \\
\text { * by infe }\end{array}$ & $\begin{array}{l}\text { hemical decom } \\
\text { mal explosion } \\
\text { rence }\end{array}$ & osition \\
\hline
\end{tabular}

energy release rate. One computational investigation also lends support to this idea that slower chemical reaction kinetic rates do provide some degree of desensitization for a given energetic material. This theoretical investigation of solid nitromethane's initiation to detonation indicates how effective slowing the rate-controlling step and its associated covalent bond rupture or dissociation can be. Results show that a, $3.45 \mathrm{Kcal} / \mathrm{mol}$ increase in a covalent bond's dissociation energy, resulting in a stronger covalent bond, causes a $30 \mathrm{Kcal} / \mathrm{mol}$ overall energy decrease in the chemical reactions occurring near the detonation shock front during a specific time interval [44]. Most interestingly, the zero point bond dissociation energy of the stronger $\mathrm{C}-\mathrm{D}$ bond is $2.3 \mathrm{Kcal} / \mathrm{mol}[45]$ more than it is for the analogous $\mathrm{C}-\mathrm{H}$ covalent bond in the various KDIE mechanistic investigations cited. This $2.3 \mathrm{Kcal} / \mathrm{mol}$ energy difference is the basis for the KDIE existence itself. Experimental verification also is needed which demonstrates that the rate-controlling covalent bond rupture of the thermochemical decomposition process is involved with an energetic material's initiation sensitivity. This possibility that the thermochemical decomposition process comprises an integral part of the initiation train sequence strongly was indicated by the charred quenched hot spot surfaces in the sub-initiated TATB, TNT, and RDX samples described earlier [26-29]. 
Experimental studies, in fact, have been reported which complete this important requirement and establish the rapid thermochemical decomposition process, its kinetically-controlled chemical reactions, and the associated rate-controlling covalent bond rupture are an integral part of the overall initiation train. First, there is correlation between an energetic compound's shock sensitivity and its critical temperature (Figure 5) [46]. Secondly, the critical temperature of an energetic material can be calculated from

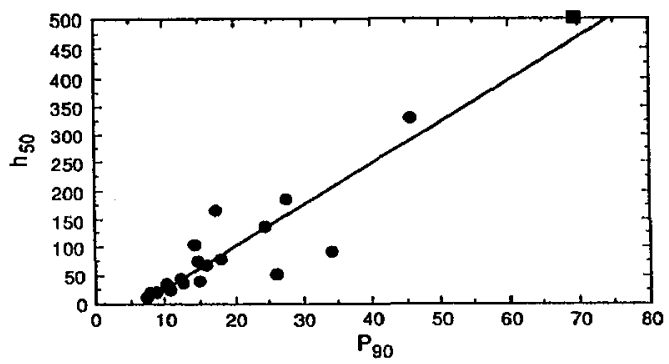

- IMPACT SENSITIVITY CORRELATES WITH SHOCK SENSITIVITY

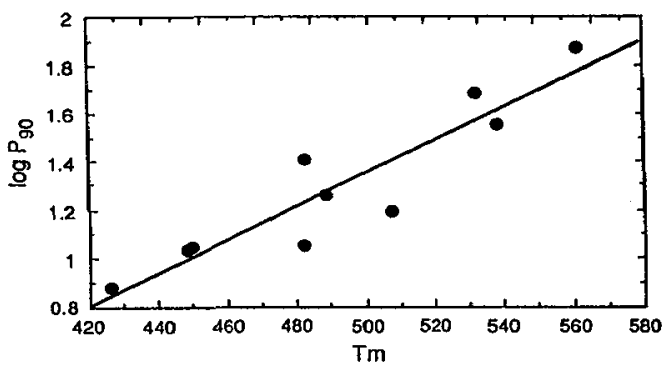

- SHOCK SENSITIVTY CORRELATES WITH CRITICAL TEMPERATURE

Figure 5. Shock Sensitivity, Impact Sensitivity, and Critical Temperature Correlations [46].

the rate constant obtained by measuring the chemical kinetics of an energy material's ambient pressure slow thermochemical decomposition process. Kinetic measurements made by IDSC analysis, when used in the the Frank-Kamenetskii Equation, provided very accurate critical temperature values $[40,47]$. The critical temperature of an energetic compound is defined as the lowest constant surface temperature at which a given sample of a specific size and shape will self-heat catastrophically. In other words, below the critical temperature a compound still can undergo a rapid thermochemical decomposition process, but it will not generate enough heat and a high enough concentration of reactive product species to become a self-sustaining entity and propagate into a thermal explosion event. The correlation (Figure 6) of shock

- ESTABLISHED RELATIONSHIPS/CORRELATIONS $(\nleftarrow-\rightarrow)$

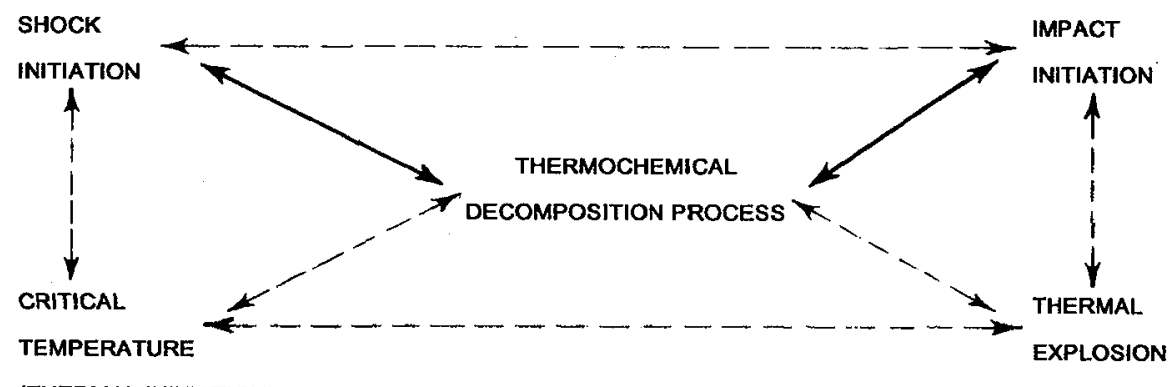

- THEREFORE: SHOCK AND IMPACT INITIATION ARE THERMAL EVENTS

C.B. Storm, J.R. Stine and J.F. Kramer, "Chemistry and Physics of Energetic Materials", Ed. S.N. Bulusu, NATO ASI Ser., Vol 309, Kluwer Academic Pubs., The Netherlands, Chapter 27, 0635

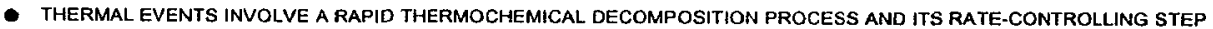

Figure 6. Thermochemical Nature of Shock Initiation, Impact Initiation, and Thermal Explosion [46]. 
sensitivity to critical temperature (dotted arrow) and the ability to calculate critical temperature from the chemical kinetics of a thermochemical decomposition process (dotted arrow), establish a direct link between the thermochemical decomposition process and shock initiation (solid arrow). The fact that impact initiation produces a thermal explosion event (Figure 6, dotted arrow), that critical temperatures are measured using the thermal explosions of the Henkin Test (dotted arrow), and that the thermochemical decomposition process of a compound (TATB and TATB-d6) produces the same KDIEdetermined rate-controlling step as that found in its thermal explosion [43b], establishes a direct link between the thermochemical decomposition process of a given energetic compound and impact initiation (solid arrow). The correlation (dotted arrow) between shock sensitivity and initiation sensitivity (Figure 6) completes Figure $5[46]$ and emphasizes the important role of the thermochemical decomposition process and its kinetically-based rate-controlling chemical reactions in the overall initiation train sequence.

The covalent bond rupture, which constitutes the rate-controlling step for an energetic compound, also depends on its inherent molecular structure. Differences in the chemical environment of a specific covalent bond may determine which structural portion of the molecule provides the rate-controlling covalent bond dissociation (Figure 7). TNT possesses two vastly different types of $\mathrm{C}-\mathrm{H}$ bonds as illustrated by their large proton NMR shifts between those in the saturated aliphatic pendant methyl

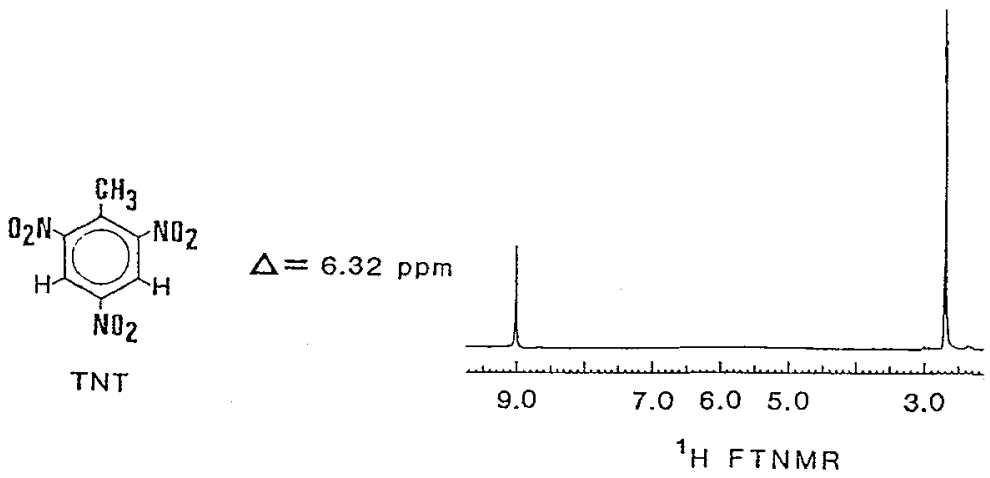<smiles>O=[N+]([O-])C1CN([N+](=O)[O-])C([N+](=O)[O-])CN1[N+](=O)[O-]</smiles>

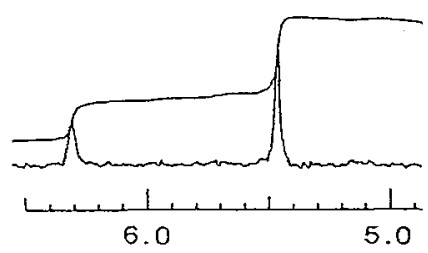

Figure 7. Proton NMR Chemical Shifts in the TNT and DNNC Molecules [1c].

group and those bonded directly to the aromatic phenyl ring. Only aliphatic $\mathrm{C}-\mathrm{H}$ bond rupture in the TNT methyl group constitutes the rate controlling step during its thermochemical decomposition process $[30,43 a]$. DNNC, however, possesses two methylene groups (4 protons) flanking the geminal dinitrosubstituted ring carbon and one methylene group ( 2 protons) situated between the two ring nitrogen atoms. While the 4 protons in the methylene groups adjacent to the geminal dinitro-substituted are not in an equivalent chemical environment with the 2 protons of the methylene group sandwiched between the ring nitrogen atoms, this difference is very slight as shown by its very small NMR chemical shift. KDIE experiments with DNNC and DNNC-d6, plus its ADIOL (2,2-dinitropropan-1,3-diol) and ADIOL-d4 precursors, seem to suggest any of these six protons can participate in DNNC's rate-controlling step during its thermochemical decomposition [48]. In other cases, a slight change in chemical structure greatly can affect an energetic compound's initiation sensitivity, possibly by causing a different ratecontrolling step to occur. Vastly different impact sensitivities are seen between 1-picryl-substituted triazoles (I and III) and the 2-picryl-substituted triazoles (II and IV) $[46,49]$. This difference (Figure 8) is explained by compounds I and III possessing a chemical structure which permits the easy elimination of the gaseous $\mathrm{N}_{2}$ molecule. Because compounds II and IV cannot eliminate $\mathrm{N}_{2}$ in such a labile manner, 
<smiles>O=[N+]([O-])c1cc([N+](=O)[O-])c(-n2ccnn2)c([N+](=O)[O-])c1</smiles>

$1.11 \mathrm{~cm}$<smiles></smiles>

III. $9 \mathrm{~cm}$<smiles>O=[N+]([O-])C1=CC([N+](=O)[O-])CC([N+](=O)[O-])=C1n1nccn1</smiles>

II. $200 \mathrm{~cm}$

IV. $67 \mathrm{~cm}$

Figure 8. Impact Initiation Sensitivity Comparison of 1- and 2-Picryl-Substituted Triazoles [49].

the chemical reactions leading to its impact initiation probably occur along a different mechanistic pathway, and, therefore, likely would involve a different rate-controlling covalent bond rupture in the rapid thermochemical decomposition portion of its initiation train sequence [2c].

The coupling of condensed phase products, which are derived from rapid thermochemical decomposition in the hot spot, with the KDIE-determined rate-controlling covalent bond dissociation, illustrates the significant role chemical kinetics play in determining the energy release rate during an initiation event. The two condensed phase products, found by XPS analysis in the quenched hot spots of a TATB sample impacted or shocked just below their initiation threshold, were the much less stable furoxan compounds and the furazan compounds (Figures 1 and 2) [26-29]. The furoxans can only form by N-H bond rupture of TATB's pendant amino group, while the furazan compounds must form from [43b]. Mechanistic KDIE thermochemical decomposition investigations with TATB and TATB-d6 revealed this mechanistic process is controlled by pendant amino group $\mathrm{N}-\mathrm{H}$ bond rupture $[40,41]$. The isolation of condensed phase furazan products from the ambient pressure thermochemical decomposition of TATB [26] further supports $\mathrm{N}-\mathrm{H}$ bond rupture as being the rate-controlling feature. Additionally, a thermal explosion study showed TATB-d 6 was significantly more difficult to initiate as determined by its higher critical temperature [40]. Further evaluation of the TATB and TATB-d6 critical temperature difference suggests pendant $\mathrm{N}-\mathrm{H}$ bond rupture to be a significant rate-controlling feature where the kinetics of the normal TATB proceed more at a higher rate and, therefore, provide energy for initiation at a lower temperature [43b]. Similar correlations with TNT $[30,50,511$ and RDX between the KDIE-determined ratecontrolling bond rupture in thermochemical decomposition, plus combustion in the case of RDX $[39,43 \mathrm{~b}]$, and the condensed phase intermediate products formed by analogous bond dissociation in quenched hot spots, also have been detected by XPS analysis $[27,29,43 \mathrm{~b}]$. One of the two XPS detected products also was detected from an impacted RDX sample using chromatography and CI mass spectral analyses [52].

Eventually, the kinetically-regulated thermochemical decomposition reactions of the condensed phase move into the gas phase, and it appears these molecular and atomic level gas-phase reactions are housed in a cellular-like physical structure formed in the detonation shock wave (Figure 1). This cellular structure of the shock wave [53-56] appears it might be formed by a physicochemical mechanism at the macroscopic level. Computational studies have simulated the mechanistic formation of this detonation cellular structure and suggested that the cellular shape is affected by energy release rates [56]. 
Experimental shock tube studies have found a relationship between the size of the macroscopic cellular structure in detonation wave fronts and tubular critical diameter. Detonation is sustained when the critical diameter is 13 times larger than an individual cell structure of the shock wave regardless of the gaseous composition of a fuel/air mixture [53]. Other experimental shock tube studies have shown that cellular structure size can be altered by adding traces of gases into a fuel/oxident mixture which promote or inhibit kinetically-regulated chemical reaction rates, even though the same overall energy of the shocked mixture remains the same [54]. The presence of these trace compounds also alter the induction time, which is defined as the length a shock wave must travel in the shock tube before a critical concentration of reactive species is attained to initiate an explosion event. Therefore, the macroscopic cellular structure size in a gaseous detonation shock wave can be altered by molecular level chemical reaction kinetics; that is, cellular structure size is determined, to some extent, by the kinetically-based rate-controlling step and probably by a specific covalent bond rupture which is present in these gaseous chemical reactions. In turn, cellular structure size is linked to the important physicochemical property of critical diameter. Energy release rates also appear to affect the degree to which an energetic material is converted to gaseous products [57]. This again suggests that chemical reaction kinetics and an associated rate-controlling chemical bond rupture could play a definite role in energy release rates in these gas phase processes. An experimental study of gas products generated by laser pulse heating of RDX showed that energy release rates determined the size of the gaseous product obtained; that is, the degree and extent of energetic material degradation. Higher energy laser pulses generated lower molecular weight gaseous fragments for the RDX molecule, while lower pulsed laser energies produced higher molecular weight gaseous products [57]. It appears the chemical kinetics which regulate the chemical reactions providing the rate-controlling mechanistic step may continue to play a noticeable role in the gas phase, especially in terms of determining energy release rates and the cell structure size in this portion of the initiation train.

Eventually, it appears these gaseous products following the detonation wave breakdown even further until atomization occurs. Traveling behind the shock wave, these atomic species, once formed, must recombine to provide the final gaseous detonation products when the detonation event terminates. The existence and importance of these atomic species achieving a steady-state thermodynamic equilibrium during detonation was determined in two separate experiments using a carbon-14/oxygen-18 labelled homogeneous explosive, BTNEA (Figure 9), and an $15 \mathrm{~N}$ labeled non-ideal explosive mixture, 20/80 Amatol [20\% ammonium nitrate (AN) containing the $15 \mathrm{~N}$ label and $80 \%$ unlabeled TNT) [58]. Even though the BTNEA compound was labeled with ${ }^{13} \mathrm{C}$ and $18 \mathrm{O}$ in its two $\mathrm{C}==\mathrm{O}$ (carbonyl) groups which would favor some retention of its ${ }^{13} \mathrm{C}==18 \mathrm{O}$ bond in the $\mathrm{CO}_{2}$ and $\mathrm{CO}$ detonation products, no bond retention was found after a full-scale bomb calorimetry detonation experiment [58]. All detonation

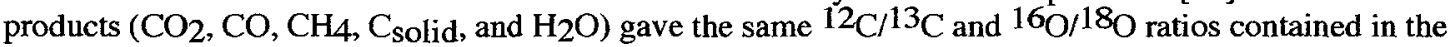
original BTNEA molecule indicating the chemical reaction kinetics were fast enough for all bonds in the

- explosion homogene (ideale): Marque'" ${ }^{13} \mathrm{C}$ et $18_{0}$ nOyauX

- hOMOGENEOUS EXPLOSIVE (IDEAL)

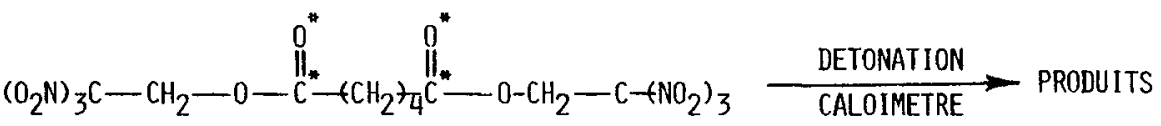

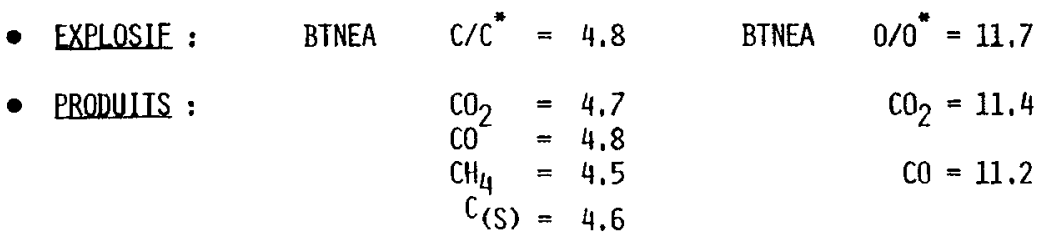

Figure 9. The ${ }^{13} \mathrm{C}$ and $18_{0}$ Isotopic Distribution in BTNEA Calorimetric Detonation Products [58].

BTNEA to rupture forming a steady-state equilibrium of atomized species prior to their recombination to final detonation products. This might suggest that the KDIE-based differences in the ease of initiation 
between TATB/TATB-d6 during its thermal explosion [40] plus TNT/TNT-d3,RDX/RDX-d6, $\mathrm{HMX} / \mathrm{HMX}-\mathrm{d}_{8}$ during their detonation event $[32,42]$, come from slower kinetic chemical reaction rate kinetics and their associated rate-controlling covalent bond rupture which occur in the earlier condensed phase rapid thermochemical decomposition process. A previously reported KDIE study conducted with HMX/HMX-d8 high pressure combustion, suggested the chemical reactions and resultant rate-controlling covalent bond dissociation occurred in the condensed phase portion of the combustion event, rather than in the chemical reactions associated with the gas phase flame portion [35,43b]. With the Amatol, the observed $14 \mathrm{~N} / 15_{\mathrm{N}}$ ratio, formed only by mixing of atomic $15 \mathrm{~N}$ species from AN and ${ }^{14} \mathrm{~N}$ atomic species from TNT, amounted only to a $12 \%$ mixing when one assumes each compound decomposed

- MELANGe explosif heterogene (nON IDEAL) MARQUE: ${ }^{*} 15_{\mathrm{N}}$ NOYAUX

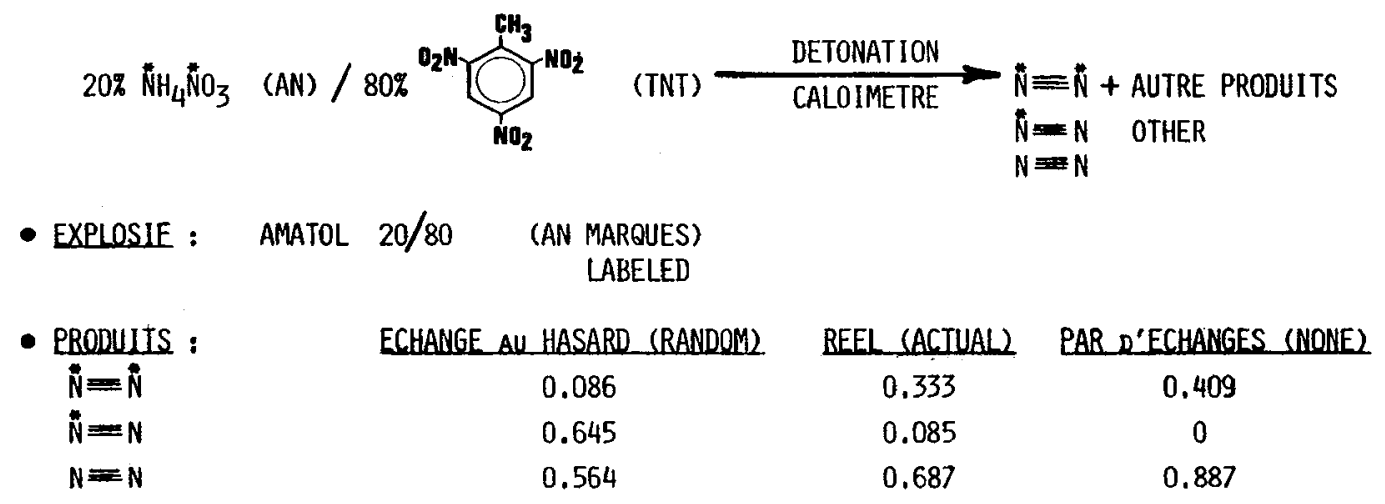

Figure 10. Isotopic ${ }^{15} \mathrm{~N}$ and ${ }^{14} \mathrm{~N}$ Exchange of AN and TNT in Amatol Calorimetric Detonation [58].

independently behind the detonation shock wave as did BTNEA. The incomplete mixing of atomic species possibly results from the recombination reaction kinetics proceeding much faster than the microscopic diffusion mechanism of these atomic species into one another [58]. This microscopic diffusion control mechanism explains why the actual macroscopic energy output from the non-ideal Amatol explosive is lower than what theoretical calculations predict.

With the formation and expulsion of final gaseous and solid residue detonation products, the complicated, sequential initiation train is completed. While detailed study must continue on the various component mechanisms, theoretical and experimental studies which reveal the coupling interactions and a possible interdependency of the component mechanisms also require further attention. In some cases, perhaps, where one with the proper insight might recognize their relationship to one another and be able to elucidate how these interactive relationships can provide a better overall understanding of the initiation event. Perhaps this general concept exhibited pictorially by Figure 1 is a starting point.

\section{CONCLUSIONS}

As discussed in this paper, several key correlations provide new insights into the complex and interactive nature of a sequential initiation train as it proceeds toward an explosive event. Firstly, past kinetic deuterium isotope effect (KDIE) investigations of slow ambient pressure thermochemical decomposition and rapid pyrolytic decomposition processes, plus of other higher pressure/temperature combustion, thermal explosion, and detonation phenomena each reveal a common rate-controlling covalent bond rupture which kinetically regulates the energy release rate of a given energetic material. Secondly, an energetic material's inherent sensitivity has been correlated to it critical temperature, and the energetic compound's critical temperature has been correlated to the kinetics and rate-controlling mechanistic step of the slow ambient pressure thermochemical decomposition process as well as to its higher order thermal explosion phenomenon. Finally, X-ray photoelectron spectroscopy (XPS) analysis with subinitiatied impact and shock studies of several energetic materials, reveals condensed phase products, generated during hot spot formation, must result from a bond dissociation which provides the ratecontrolling step observed during its ambient pressure thermochemical decomposition process. This 
suggests that the rate-contolling mechanistic feature of an energetic material's thermochemical decomposition process plays a significant role in its sensitivity characteristics. Additionally, examples have been noted where energy release rates can affect detonation wave's cellular structure, size, and induction times which define when a sufficient concentration of reactive species are generated in the gas phase to effect detonation. The correlation too of chemical kinetics to variations in detonation wave structure during gaseous shock tube detonation, further suggests that kinetically-regulated chemical reactions and their associated rate-controlling bond dissociation step must contribute significantly to determining energy release rates present in the gaseous portion of the initiation train sequence. They may, however, be much faster than the rate-controlling bond dissociations which controls the kineticallydriven chemical reactions of the condensed phase.

These correlations collectively suggest the following: (1) chemical reaction kinetics play a significant role in an initiation train sequence (Figure 1 ); (2) a slower kinetically regulated rate-controlling mechanistic step can cause noticeable desensitization of an energetic material; and, (c) the kinetically regulated rate-controlling step, usually identified as a covalent bond dissociation or rupture and detected by the condensed phase KDIE approach, is one of several desensitizing mechanistic factors found in the initiation train concept. This could mean that by disrupting or altering any one of the several mechanistic processes below its an unspecified threshold, significant desensitization might be achieved for a given energetic material. Alternatively, by collectively altering the pathway or reducing the propagating rate of several mechanistic factors (eg. hot spot rate formation or reactive product species threshold concentrations), each by a small degree, an overall additive effect might be achieved which could significantly desensitize a given energetic material. In order to achieve this type of sensitivity control specific mechanisms operating in the explosive train sequence must be more fully elucidated, and just as importantly, the interactions among them and the influence one mechanism has upon another must be determined. Only then will we develop a complete picture of the initiation event which permits explosive sensitivity prediction and design through sound and accurate scientific principles.

\section{ACKNOWLEDGEMENTS}

The author expresses his sincerest appreciation to Dr.Simone Odiot and her co-chairmen of the 2nd International Workshop on Microscopic and Macroscopic Approaches to Detonation, Dr. Ronald Armstrong (USA) and Dr. Anatoly Dremin (Russia), and to members of the Organizing and Scientific Committees for the generous invitation to participate in this scientific gathering. Dr. Frank Walker, an early USA pioneer in hot spot theory and its relevancy, provided the author timely encouragement concerning this initiation train concept. Substantiative scientific discussions with Dr. Jacques Boileau (France) over a number of years also have been very helpful as have been the enthusiasm, encouragement and discussions of Raymond N. Rogers (Los Alamos, NM (USA)] concerning thermal chemistry and the KDIE research the author and his colleagues have conducted during the past 19 years. Alliance Pharmaceutical Corp. provided some needed support in making arrangements to participate at this workshop.

\section{REFERENCES and NOTES}

[1] Portions of this paper were presented at the following conferences: (a) Shackelford S.A., "Energetic Material Sensitivity and the Rate-Controlling Mechanistic Step", Workshop on Desensitization of Explosives and Propellants", Rijswijk, The Netherlands 11-13 November 1991; (b) Shackelford S.A., "Energetic Material Initiation and Sensitivity. I. Kinetically Regulated Rate-Controlling Mechanistic Steps", Eighteenth International Pyrotechnics Seminar, Breckenridge, Colorado (USA), 13-18 July 1992; and, (c) Shackelford S.A., "Energetic Material Initiation Sensitivity. II. Chemical Structure/Mechanism Relationship to Sensitivity", Eighteenth International Pyrotechnics Seminar, Breckenridge, Colorado (USA), 13-18 July 1992.

[2] Author's new affiliation is Alliance Pharmaceutical Corp. located at the address given on the title header. APC is not involved in any facet of energetic materials research, technology, or development. The sole focus of APC is the use of perfluorocarbon compounds and their derivatives for oxygen transport (synthetic blood substitutes), gas and tissue interchange (liquid breathing), and medical imaging (MRI, X-ray, Ultra-Sound) applications.

[3] Field J.E., Swallowe,G.M., and Heavens S.N., Proc. R. Soc. Land., A382 (1982) 23 1-244. 
[4] Mohan V.K., Field J.E., and Swallowe G.M., Combustion Sci. and Tech., 40 (1984) 269-278.

[5] Mohan V.K. and Field J.E., Comb. and Flame, 56 (1984) 269-277.

[6] Armstrong R.W., Coffey C.S., and Elban W.L., Acta Metall., 30 (1982) $2111-2116$.

[7] Elban W.K., Hoffsommer J.C. and Armstrong R.W., J. Mater. Sci., 19 (1984) 552-566.

[8] Armstrong R.W., "Dislocation Pile-Up Mechanism for Initiation of Energetic Crystals", NATO Advanced Study Institute on Chemical Reaction Dynamics, Iraklion (Crete), Greece 25 August-7 September 1985 .

[9] Armstrong R.W. and Elban W.L., Microindentation Techniques in Materials Science and Engineering, ASTM STP 889, Eds. Blau P.J. and Lawn B.R. (American Society in Testing and Materials, Philadelphia, 1986) pp. 109-126.

[10] Elban W.L., Armstrong R.W., Yoo K.C. Rosemeirer R.G, and Yee R.Y., J. Mater. Sci., 24 (1989) $1273-1280$.

[11] Miller PJ., Coffey C.S., and DeVost V.F., J. Appl. Phys., 59 (1986) 913-916.

[12] Leiber C.O., J. Hazard Mater., 12 (1985) 43-64.

[13] Leiber C.O., J. Hazard Mater., 13 (1986) 311 1-328.

[14] Leiber C.O., "On Some Shortcomings in the Macroscopic Plane Wave Model of Detonation", Thirteenth International Pyrotechnics Seminar, Grand Junction, Colorado (USA) 11-15 July 1988.

[15] Leiber C.O., "Detonation Model with Spherical Sources Smooth and Rough Pressure Fronts, Dark Waves", Thirteenth International Pyrotechnics Seminar, Grand Junction, Colorado (USA) 11-15 July 1988.

[16] Leiber C.O., "Detonation Model with Spherical Sources C: Quasicontimuum Approach; Slow and Low Velocity Detonation", Fifteenth International Pyrotechnics Seminar, Boulder, Colorado (USA) July 1991.

[17] Leiber (..O., "Detonation Model with Spherical Sources D: Fracture Dynamics of Initiation - Dense Quasihomogeneous Solids", Fifteenth International Pyrotechnics Seminar, Boulder, Colorado (USA) July 1991 .

|18| Leiber C.O., "Detonation Model with Spherical Sources E: Dynamic Particle Motion - Initiation of Heterogeneous Materials", Sixteenth International Pyrotechnics Seminar, Jonkoping, Sweden 24-28 June 1991.

[19] Leiber C.O., "Detonation Model with Spherical Sources F: Dynamic Void Mobilities - Alteration of the Hugoniots by Bubble Flow', Seventeenth International Pyrotechnics Seminar, Beijing, China 28-31 October 1991.

[20] Leiber C.O., "Detonation Model with Spherical Sources G: Dynamic Void Mobilities - HVD Initiation of Liquid Explosives", Seventeenth International Pyrotechnics Seminar, Beijing, China 28-31 October 1991.

[21] Armstrong R.W. and Elban W.L.,"Dislocation Mechanics Aspects of Desensitization to Impact or Shock", Workshop on Desensitization of Explosives and Propellants", Rijswijk, The Netherlands 11-13 November 1991.

[22] (a) Odiot S., Peyrard M., and Mijoule C., "Molecular Theory for a Cooperation Mechanism for Shock Induced Detonation Waves in Molecular Crystals: Nitromethane", NATO Advanced Study Institute, Iraklion (Crete), Greece 25 August-7 September 1985; (b) Peyrard M., Odiot S., and Oran E., 
J. de Physique (Colloque C4), 48 (1987) 291-301; and (c) Odiot S. and Peyrard M., J. de Physique (Colloque C4), 48 (1987) 393-395.

[23] Dick J.J., J. Phys. Chem., 97 (1993) 6193-6196.

[24] (a) Dick J.J., Mulford R.N., Spencer W.J., Pettit D.R., Garcia E., and Shaw D.C., I. Appl. Phys., 70 (1991) 3572-3587; and, (b) Dick J.J.,"Orientation Dependence of the Shock Initiation Sensitivity of PETN: A Steric Hindrance Model", Workshop on Desensitization of Explosives and Propellants, Rijswijk, The Netherlands 11-13 November 1991.

[25] Samirant M., J. de Physique (Colloque C4), 48 (1987) 85-98.

[26] Sharma J., Hoffsommer J.C., Glover D.J., Coffey C.S., Santiago F., Stolovy A., and Yasuda S., Shock Waves in Condensed Matter, J. R. Asay, R.A. Graham and G.K. Straub Eds. (Elsevier Science Publishers, Amsterdam, 1983) pp. 543-546.

[27] Sharma J., Hoffsommer J.C., Glover D.L., Coffey C.S., Forbes J.W., Liddiard T.P., Elban W.L., and Santiago F., "Sub-Initiation Reactions at Molecular Levels in Explosives Subjected to Impact and Underwater Shock", 8th Symposium (International) on Detonation (U. S. Government Printing Office, Washngton, D.C., 1987) pp. 725-733.

[28] Sharma J., Forbes J.W., Coffey C.S., and Liddiard T.P., Shock Waves in Condensed Phase Matter, S.C. Schmidt and N.C. Holmes Eds. (Elsevier Science Publishers, Amsterdam, 1987) pp. 565-568.

[29] Sharma J., Forbes J.W., Coffey C.S., and Liddiard T.P., J. Phys. Chem., 91 (1987) 5139-5144.

[30] Shackelford S.A., Beckmann J.W., and Wilkes, J.S., J. Org. Chem., 42 (1977) 4201-4206.

[31] Shackelford S. A., Coolidge M.B., Goshgarian B.B., Loving B.A., Rogers R.N., Janney J.L., and Ebinger, M.H., J. Phys. Chem., 89 (1985) 3118-3126.

[32] Bulusu S.,Weinstein D.I., Autera J.R., and Velicky R.W., J. Phys. Chem., 90 (1986) 4121-4126.

[33] Behrens R.Jr., J. Phys. Chem., 94 (1990) 6706-6718.

[34] Behrens R.Jr. and Bulusu S., J. Phys. Chem., 95 (1991) 5838-5845.

[35] Shackelford S.A., Goshgarian B.B., Chapman R.D., Askins R.E., Flanigan D.A., and Rogers R.N., Propellants, Explos., Pyrotech., 14 (1989) 93-102.

[36] Rodgers S.L., Coolidge M.B., Lauderdale W.J., and Shackelford S.A., Thermochim. Acta, 177 (1991) 151-168.

[37] Behrens R.Jt. and Bulusu S., J. Phys. Chem., 96 (1992) 8877-8891.

[38] Behrens R.Jr. and Bulusu S., J. Phys. Chem., 96 (1992) 8891-8897.

[39] Shackelford, S.A., Rodgers S.L., and Askins R.E., Propellants, Explos., Tech., 16 (1991) 279-286.

[40] Rogers R.N., Janney J.L., and Ebinger M.H., Thermochim. Acta, 59 (1982) 287-298.

[41] Sharma J., Garrett W.L., Owens F.J., and Vogel V.L., J. Phys. Chem., 86 (1982) 1657-1661.

[42] Bulusu S. and Autera J.R., J. Energetic Matls., 1 (1983) 133-140.

[43] For a Review: (a) Shackelford S.A., Chemistry and Physics of Energetic Materials, S. Bulusu Ed. (Kluwer Academic Press, The Netherlands, 1990) pp. 413-432; and, (b) Shackelford S. A., Chemistry and Physics of Energetic Materials, S. Bulusu Ed. (Kluwer Academic Publishers, The Netherlands, 1991) pp. 433-456. 
[44] Odiot S., Chemistry and Physics of Energetic Materials, S. Bulusu Ed. (Kluwer Academic Publishers, The Netherlands, 1991) pp. 102-130.

[45] Allinger N.L., Cava M.P., DeJongh D.C. Johnson C.R., Lebel N.A., and Stevens C.L., Organic Chemistry (Worth Publishers, Inc., New York, 1971) pp.300-301.

[46] Storm C.B., Stine J.R., and Kramer J.F., Chemistry and Physics of Energetic Materials, S. Bulusu Ed. (Kluwer Academic Publishers, The Netherlands, 1991) pp. 605-640.

[47] Rogers R.N., RCEM Rpt. A-04-87, (4 Nov 1987) pp. 16-35.

[48] Shackelford S.A. and Goldman J.F.,"Intramolecular Mechanistic Thermochemical Decomposition Studies of 1,3,5,5-Tetranitrohexahydropyrimidine (DNNC) and Its Deuterium Labeled Analogues", 203rd National Am. Chem. Soc. Mtg., San Francisco, CA (USA) 5-10 April 1992.

[49] Storm C.B., Ryan R.R., Ritchie J.P., Hall J.H., and Bachrach S.M., J. Phys. Chem., 93 (1989) 10001007.

[50] Rogers R.N., Anal. Chem., 39 (1967) 730-733.

[51] Dacons J.C., Adolph H.G., and Kamlet M.J., J. Phys. Chem., 74 (1970) 3035-3040.

[52] Hoffsommer J.C., Glover D.J., and Elban W.L., J. Energetic Matls., 3 (1985) 149-167.

[53] Lee J., "Combustion and Turbulence I", NATO Advanced Study Institute on Chemical Reaction Dynamics, Iraklion (Crete), Greece 25 August-7 September 1985.

[54] Dupre G., J. de Physique (Colloque C4), 48 (1987) 397-403.

[55] Paillard C., J. de Physique (Colloque C4), 48 (1987) 405-414.

[56] Oran E.S., Kailasanath K., and Guirguis R.H., J. de Physique (Colloque C4), 48 (1987) 105-117.

[57] Pfeil A., Eisenreich N., and Krause H., J. de Physique (Colloque C4), 48 (1987) 209-221.

[58] McGuire R.R., Ornellas D.L., and Askt I.B., Propellants and Explos., 4 (1979) 23-26. 